\title{
Steering Clear of the Rocks: A Look at the Current State of Oral History Ethics in the Digital Age
}

\author{
Mary Larson \\ Oklahoma State University
}

Published in The Oral History Review: The Oral History Review, Volume 40, Issue 1, 1 January 2013, Pages 36-49, https://doi.org/10.1093/ohr/oht028

The discussion of ethical considerations within oral history can be tidily summarized by paraphrasing a line from a recent pirate movie franchise: In life there are only two things that matter-what a man can do and what a man will do. This reflects the fact that, overall, the ethical topics of conversation in oral history tend to be divided into two main categories-legislated (what one can do) and voluntary (what one will do). While the former are enforced through the oversight of Institutional Review Boards in the U.S. and other countries and through restrictions set by legally binding documents, the latter are exercised in response to oral historians' respect and concern for their narrators. While these two facets are not exclusive of each other, they reflect the fact that the methodology's ethical considerations are driven both by legalities and by individual consciences. When the Oral History Association revamped its Evaluation Guidelines and adopted a new Principles and Best Practices document in October 2009, it was, in part, with these two components in mind.1

Institutional Review Boards, or IRBs, have been a topic of considerable discussion in oral history over the last fifteen years. For those unfamiliar with IRBs, they are committees that oversee research conducted on or with human subjects so as to ensure that studies are executed in an ethical manner, and these committees are generally associated with colleges, universities, and state or federally funded agencies. Oral historians not affiliated with such institutions or projects are usually not under the purview of an IRB and are therefore free from their oversight (although not, of course, from the related ethical considerations). The relationship of IRBs to oral history projects has been a controversial and moving target over the last decade and a half, in part because, while IRBs have been provided with a loose set of federally mandated guidelines that they must follow, there is a large degree of variance in the amount of control they attempt to exercise over different types of research. The issue is a complicated one, and, since the emphasis of this article is on a broader view of ethics rather than a specific view of IRBs, what follows is only a brief summary of trends in this area. (Those seeking more detail or needing guidance on specific issues may consult Zachary Schrag's 2010 book, Ethical Imperialism, and Linda Shopes's 2011 essay, "Human Subjects and IRB Review," both of which treat the subject in considerably more depth.2)

Regarding the types of work covered, most IRBs originally focused only on biomedical studies (in part as a result of the infamous Tuskegee syphilis research project), but, during the 1980s and 1990s, boards were increasingly directing their attention to the social sciences and humanities, thus involving many oral historians who had been exempt from this type of institutional scrutiny in the past. Beginning in the 1990s, particularly, there was a marked lack of standardization from one IRB to another in terms of the control committees had over even low-risk oral history projects, which resulted in no small amount of confusion. In 1998, in order to try to clarify for IRBs just what it is that oral historians do, the Oral History Association (OHA), together with the American Historical Association (AHA) and the Organization of American Historians (OAH), began to work more closely with IRBs. Since the methodology of oral history 
was relatively unknown to many of the boards, there was a lack of understanding of what oral history actually entailed.

There were two main issues that the professional organizations were trying to address for oral history projects that posed little or no risk to narrators. First, a number of IRBs had tried to enforce anonymity as a condition of interviewing, a concern which likely arose from the discussion of confidentiality in 45 CFR 46, the federal document governing IRBs. The relevant passage states that researchers must be sure that "when appropriate" there be adequate provisions to protect privacy and maintain confidentiality; some IRBs, however, took this to mean that confidentiality was required in all situations.3 Most oral historians understand that this option is in place as a means of mitigating any harm that might come to a person because of information that he/she might relate in the course of an interview, but, in general, anonymity is antithetical to the goals of oral history if there are no exacerbating risk factors. As the OHA's Principles and Best Practices History notes, "Because of the importance of context and identity in shaping the content of an oral history narrative, it is the practice in oral history for narrators to be identified by name. There may be some exceptional circumstances when anonymity is appropriate, and this should be negotiated in advance with the narrator as part of the informed consent process." 4 The confidentiality requirement was mostly short-lived throughout the U.S.; it fell away as IRBs became more aware of the goals and methods of oral historians, as well as the lack of risk reflected in most oral history projects. But it still occasionally poses a problem in institutions where IRBs are less familiar with oral history.

The second issue that illustrated a lack of understanding about oral history methodology was the required submission of question lists for each proposed project. Some IRBs did not understand that oral historians take a very different approach to their research than do some other disciplines, such as sociology, where a preset questionnaire may be designed to elicit data that can be interpreted into general statements about a population or particular demographic group. Because of this misconception, some IRBs were requiring the submission of exact question lists for each oral history protocol submitted for review. The point of oral history, however, is that each interview is individualized, tailored to one person and is usually not meant to result in anything generalizable. The crux of the matter, as with the anonymity discussion, was individuality. For those IRB members who were better informed about the goals of oral history, there was a dawning realization that submitting one immutable question list for an entire project would be untenable.

Over time, most IRBs have become more aware of oral history practices, and that is in large part due to the efforts of the affiliated professional organizations- $\mathrm{OHA}, \mathrm{AHA}$, and $\mathrm{OAH}$-that have been working with the federal Office of Human Research Protection (OHRP) to clarify IRB requirements. In October 2003 , the OHRP determined that oral history interviewing projects, in general, do not involve the type of activity defined by Health and Human Services regulations and that they are therefore excluded from IRB oversight. George Pospisil of the OHRP explained at the OHA's annual meeting that year that the decision regarding the application of 45 CFR 46 was based on how the term "research" was defined by the government, namely, "a systematic investigation, including research, development, testing, and evaluation, designed to develop or contribute to generalizable knowledge." 5 The OHRP found that most oral history projects, with their emphasis on individuality and context, do not attempt such "systematic investigation." (There are some exceptions, but they are primarily graduate research projects using oral histories to prove or disprove particular hypotheses, which is something that oral history programs do not, in general, do.) The OHRP noted that if the principles and standards of the OHA were followed, in most instances practitioners would be in compliance with good scholarly practice and would not require IRB oversight. This was reaffirmed in communications by the OHRP's Michael Carome with Donald 
Ritchie and Linda Shopes, who had worked on the original policy statement with the OHRP.6 Many federal agencies, including the Smithsonian Institution, have taken this recommendation to heart and exempt the majority of their oral history projects from IRB review.7 Others, like the National Endowment for the Humanities, which does sponsor oral history work through some of its grant programs, were never signatories to the Common Rule agreement in the first place, and thus projects supported by those agencies do not automatically require IRB oversight. 8

The IRB scene is not static, however, and the seas may be shifting yet again, although it is unclear how this particular turn of the tide might affect oral history. On July 22, 2011, an Advanced Notice of Proposed Rule Making was issued by Health and Human Services in regard to possible changes to the Common Rule, with a request for comments to be submitted by October 26 of that year.9 There were over eleven hundred responses (approximately 12 percent of which referenced oral history specifically), but perhaps because of the sheer amount of feedback, there have yet to be any updates posted by the OHRP on the process or results of their deliberations.10 A number of the proposed policies, however, might seriously impact oral history methodology going forward, either for better or worse, so it will be important for practitioners to remain alert for any developments.

While IRBs are one of the "legislated" prongs of the ethics discussion being addressed in this article, the other involves consent and release forms (the latter are also known as "deeds of gift" or "copyright assignments"). These are the documents that allow archival repositories to make recordings and transcripts available to the public for research. Consent forms are often required by IRBs or other regulatory bodies, and they essentially list the rules of engagement for a project, describing how interviews will be conducted, notifying narrators of their rights, and requiring the signature of the interviewee (and sometimes the interviewer). Release forms, on the other hand, detail the circumstances under which an oral history can be made available for research or used for publications or other products. Any restrictions are generally attached to this document, which also requires the signature of the narrator.

Interestingly, the number of necessary signatures on release forms seems to have changed in accordance with theoretical approaches to oral history. Up through the 1970s, at least, many repositories would accept oral histories with a deed of gift signed by whoever happened to have possession of them. It need not have been the interviewer or interviewee, and this practice reflected the forms common to most archives, where the physical owner of a document or photograph had the right to donate it, regardless of whether or not they actually held copyright to the item. The practices of oral history programs around the U.S. varied, but the signatory of choice generally changed throughout the 1980s, when chroniclers were finally acknowledged as having a major role in the telling of their own stories. The required signature shifted from that of the donor to that of the chronicler, although there was still often only one signature line on the release forms. As the dialogic nature of oral history became more accepted, however, and as the profession recognized the dual importance of the interviewer and interviewee in the collaborative venture, both signatures began to be required on the forms, a practice which tends to be the norm at the majority of institutions currently.

Most of the forms used by oral history programs at this point in time involve the transfer of copyright from the narrator (and interviewer) to a repository, but it is not unusual for universities to have clauses in their paperwork that allow chroniclers (and, again, interviewers) to use the work for their own purposes during their lifetimes. These permit researchers to acquire the rights they feel are necessary for an archival institution to make the oral histories available, while still providing for creative use of the interviews by the collaborative partners in the process. This serves to mitigate a situation that makes 
many oral historians squeamish, since transfer of copyright is often seen as required in order for institutions to make material accessible, but, at times, it can, quite frankly, be an uncomfortable request to make of an interviewee.

For many years, most oral historians have been acutely aware of possible power discrepancies in their work, and, as a result, copyright transfer has been an area of potential distress for many. There is a relatively new trend, however, that might resolve the situation to everyone's satisfaction. This is the recent movement toward the use of Creative Commons licensing for oral histories, with the underlying goal being to allow narrators to keep the copyright to their interviews, while still providing for researcher access through repositories or online distribution. Creative Commons was founded in 2002 as a way of making material more open and easily available, and their website outlines six different licensing combinations, with options based upon a number of factors.11 (They have even created a license "wizard" that can walk a potential user through the available types based on a list of pertinent questions.12) All the licenses share the characteristic of "attribution," which means that no matter how the work is ultimately used, proper reference must be made to the originator of the work. Further licensing decisions can be based on whether or not derivative works can be created (using something other than the entire piece), whether or not the item can be reused for commercial purposes (or for noncommercial projects only), and whether or not any use must be covered by the same Creative Commons guidelines. The last is referred to as the "Share Alike" option, which requires anyone using covered material to license it in similar fashion.

While some oral history projects and programs have been experimenting with Creative Commons approaches to copyright issues, most of the conversation on the topic has been in more informal, online venues, such as e-mail lists. An exception is an article authored by Jack Dougherty and Candace Simpson, "Oral History Interviews-Who Owns Oral History? A Creative Commons Solution," which outlines their use of a new model of release form.13 Since oral history is, at heart, a largely populist methodology with deep concerns about issues of power and privilege, a move to this different type of agreement may be the next sea change for practitioners and repositories.

There are additional ethical concerns in oral history, however, beyond those outlined above, and, if anything, they are more complicated because of their often situational nature. Most of these worries revolve around the use of oral history materials in particular contexts, and these issues have become more complex as technologies have evolved. The most pressing questions have generally dealt with the use of old (but legally valid) deeds of gift to release materials for new digital platforms. The essential question is this: even if a program has clear copyright to an interview, does it have an ethical right to do anything it likes with that oral history, even if the chronicler could not have foreseen a particular possible use? From an ethical standpoint, what does it mean to put interviews online that were completed decades before the Web was even a twinkle in a Silicon Valley eye?

When the possibility of hosting material online (or even via basic electronic platforms) first arose in the mid-1990s, presenting oral histories in that manner was not easy. Neither the hardware nor the software were quite up to the task. The author can personally recall the immense joy in the Project Jukebox office at the University of Alaska Fairbanks when the first computer with $32 \mathrm{MB}$ of RAM arrived, allowing a marked increase in the processing speed available for audio file conversion. Additionally, in those beginning years, HTML coding was all done by hand, requiring oral historians to either learn to code themselves (which some of us did) or to hire IT specialists who could do the work for them. 
Because these early digital projects were then so complicated and time-consuming, however, it also meant that oral history programs considering such undertakings were very thoughtful about the entire process. Project directors were not simply concerned about RAM, throughput speeds, and interface design. Rather, because these endeavors required such an investment of person- hours and resources, every aspect was scrutinized before proceeding, and that included the ethical considerations. What were the implications of placing material online-for the interviewees, their communities, the oral historians, and the archives?

Discussions about these topics were prominent at OHA meetings in the late 1990s and early 2000s, but as making interviews available on the Internet became a simpler process - with code editors, Cascading Style Sheets, YouTube, and WordPress - the conversation seemed to die down. As the costs of launching online ventures lessened, the dialog about digital ethics seemed to decrease exponentially as well, perhaps due to the fact that, with projects being more manageable, not as much thought had to be put into all aspects of their production. That was not necessarily a positive result, since, as can be seen later in this article, not all of the ethical dilemmas with online access have been resolved. Ultimately, the impact has probably been more far-reaching than any of us might have imagined.

Privacy issues were one of the first considerations, perhaps because they were the most obvious. When an interviewee signed a release form for an oral history prior to the digital age, he/she would probably have been safe in assuming that, at that time, the recording or transcript would be made available only at a local library or archive. In the 1990s, however, it became possible to place oral histories online, which begged the question of whether or not programs had an ethical right to do that even if they had a legal right. An archive may very well have had release forms for interviews, and those forms may have deeded copyright to the repository, but did online use of material really seem to be in line with the original wishes of the donor? What was the qualitative difference between having one's story available in a reading room versus having it accessible from halfway around the world at the click of a mouse? The OHA's Principles and Best Practices provides the following guidance:

The repository should comply to the extent to which it is aware with the letter and spirit of the interviewee's agreement with the interviewer and sponsoring institution. If written documentation such as consent and release forms does not exist then the institution should make a good faith effort to contact interviewees regarding their intent. When media become available that did not exist at the time of the interview, those working with oral history should carefully assess the applicability of the release to the new formats and proceed-or not-accordingly.14

Tied closely to that consideration, and also a matter of a repository's responsibility to chroniclers, was the issue of an archive being able to maintain control over material were it to go online. When researchers have accessed material within a reading room in the past, there was a sense that archival staff had some influence over how the interviews could be used, since they met with patrons and had them sign forms acknowledging the institution's use policies. While the discussion of online platforms brought up the implications of losing that sort of control, many practitioners questioned whether there was really anything being lost, in concrete terms. Researchers could already take notes and record passages from transcripts, even in a reading room, and, as use copies of electronic versions of transcripts and audio files became readily available for checkout or distance delivery, there was always the chance that copying could take place in spite of everyone's best efforts. The issue was whether or not this would be more commonplace if materials were to go online.15 As oral history is largely an endeavor built on a relationship of trust between interviewers and interviewees, these considerations 
were not insignificant matters, and oral historians and archivists were rightly concerned over how the situation might evolve.

The matter of paperwork (consent and release forms), at least going forward, had perhaps the simplest solution. Since the mid-1990s, most oral history programs have changed their release and/or consent forms to specifically reference future possible uses of interviews, including, but not limited to, electronic reproduction and online dissemination. Language has been drawn broadly enough that there is the potential for other formats at later dates, and pre-interview discussions with narrators have begun to include a variety of possibilities for distribution of their oral histories. But what of programs that want to use their older recordings, which, in some cases, amount to thousands of hours of information that would be of interest to researchers? What do they do if they want to conform to current standards? How does an institution "carefully assess the applicability of the release to the new formats," per the Principles and Best Practices?

Repositories have chosen four basic ways of addressing these issues for preexisting interviews. (It should be noted that some of these paths were adopted prior to the appearance of the new OHA guidelines in 2009, so they are not necessarily interpretations of, or reactions to, that document.) The first approach presumes that the legal and ethical rights to an interview are equivalent. Programs taking this route have proceeded under the assumption that narrators who clearly deeded their interviews to a repository, without restriction, had every intention of making those materials available to the public, and these collections have placed their holdings online on the strength of their original consent or release forms.

Trending in the opposite direction, a large number of programs have made detailed finding aids available online, complete with subject listings that allow scholars and the interested public to see what topics are addressed within their collections, while at the same time keeping the actual interviews offline. This makes it easier for researchers to locate material, but the repository still maintains a degree of physical control, at least, over the interviews. It is not necessary to try to ascertain the "letter and spirit" of the original agreements with the interviewees because access is essentially no different than it would have been previously, since anyone wanting to get a copy of an interview still needs to be in contact with the repository.

Other programs have used a third approach and have made their older recordings available online only in excerpted forms. In some respects, this is an attempt to fall within "fair use" guidelines as generally understood for copyright purposes, although it should be noted that most of these programs tend to have clear copyright to the recordings and are simply using "fair use" parameters as a way of gauging what amount of material might be ethically appropriate to place online. These programs reason that if an excerpt would be acceptable under "fair use" standards, then it would similarly qualify as a nondamaging use under other circumstances as well.16

Some repositories, however, like the University of Alaska Fairbanks (UAF), have taken a fourth path and have made a wholesale attempt to recontact large numbers of chroniclers before making their information available online, exercising due diligence in trying to find former interviewees to get their approval for a wider dissemination of their oral histories. At UAF, this extensive undertaking was funded by the National Science Foundation and involved numerous letters, many discussions and community meetings, and a great expenditure of overall effort, but the program felt that these steps were necessary to accurately gauge the wishes of the original interviewees. The result was that a vast 
majority of chroniclers and communities were excited about online use of their materials, with only a few requesting that their oral histories not be placed on the Web.

While these approaches variously address the topic of narrator consent for the online dissemination of interviews, they do not speak to the problem, mentioned earlier, of institutional control of materials. Many oral historians are less worried about intentional online piracy than they are about unintentional misuse of interviews, if only because they think that the former is highly unlikely among those accessing oral history sites. As more material of all types becomes easily accessible on the Web, many people are under the misapprehension that "easily available" equals "freely available" (that is, that files are in the public domain). The general sense is that online researchers may be more likely to misappropriate oral histories out of ignorance than through any intent of malice; therefore, some repositories are approaching the issue from an educational standpoint. They place clear copyright notices on all online resources, and/or they have their institutional use policies prominently displayed on their sites or attached to each interview.17 These steps openly denote the rights of the repository (and, by extension, the narrators), which puts casual researchers on notice and is additionally useful in the rare event that legal action might be needed due to any use-policy violations.

While institutional control and unintended violations of privacy were two issues that emerged early in the digital age, other considerations have taken longer to appear on the horizon. Perhaps the one that has the greatest impact on how future oral historians conduct their work has to do with the way community relations have been changed by online projects. In the past, when oral history collections were placed in archives and made available through reading rooms, practitioners could expect that very few community members would actually see the results of their work. Narrators often received copies of their interviews, of course, but few people would take the step of visiting an institutional library or museum to look at, or listen to, a completed project. What that meant in practical terms was that there was much less pressure on researchers to be accountable, whether to entire communities or to multiple factions or interests within them. While there have always been oral historians who have gone the extra mile to be engaged with a community and to preserve those relationships, they largely did so out of their own personal senses of ethics rather than because of any external impetus.

When projects become easily accessible online, however, collections are opened up to everyone-those who participated and those who did not, those who were interested at the time and those who were not, those who agreed with the project and those who did not. It is all out there for the entire community to see and assess, and people's reaction to a site, exhibit, or database can color relationships with a group or neighborhood for years to come. Researchers who were not previously aware of the impact of their projects on communities had to become much more cognizant of, and intentional about, how they approached their work, as they are now held considerably more accountable. This is, of course, a positive thing, but it has been an adjustment for some. Also, in cases where there are particular sensitivities because of the nature of oral history collections, decisions have been made not to make material available online - not because of any backlash that oral historians might experience, but because of potential ramifications for members of particular communities.

The silver lining, of course, is that easy discoverability of projects also brings with it wonderful opportunities for collaboration. If people understand that an undertaking will be representing their community, in their voices, to the larger world, they are much more likely to be engaged stakeholders who will be involved in interviews and assist with the acquisition of related materials. Participants can also play a larger part in building the context that is so necessary for oral history websites if outsiders are to understand particular communities. And they can have greater ownership over what, in past 
years, may have been more of a researcher-driven product. Again, while there have always been oral historians who approached projects in this way, the cooperative development of an online presence is a new way to encourage participation.

While researchers have a responsibility to communities, they also have to be accountable to individual chroniclers, and negotiating that accountability has been an ethical concern in oral history since long before digital platforms became available. Online presentation and dissemination of materials tend to throw the previous discussions into high relief because the repercussions can be exponentially greater. Accountability relates, in turn, to the privacy concerns noted earlier in this piece but with a twist. Earlier, the emphasis was on determining whether or not interviews could be placed online because of release or consent form status. That is, when a person signed a release form, could he/she have had a reasonable expectation that his interview would be distributed by something as far reaching as the Internet? This second issue of responsibility to individuals, however, focuses on a slightly different question. What should oral historians do about narrators who have voluntarily signed consent and release forms and are willing to put their oral histories online even when the content has the potential to be damaging to them or others in later years? How should repositories or researchers proceed in those instances?

This matter has been discussed at length in OHA annual meeting sessions over the years, and wellrespected, thoughtful oral historians have come down on different sides of the digital fence.18 Some have argued that researchers have a responsibility to protect their narrators as part of the good-faith contract they enter into through the interview process and that, as such, they should keep the possibly detrimental items from being widely disseminated online. Others have responded by saying that that approach smacks of paternalism and that if the narrators are competent adults over the age of majority who have indicated that they understand any possible risks (limited or not), then their wishes to have their material placed online should be respected.

This discussion has been complicated in more recent years by a sense that the general public has an increasingly cavalier attitude toward privacy and an apparent lack of understanding regarding the possible longevity of items placed on the Web and the repercussions that might result. While research into this topic indicates that people across all age groups have aspirations toward privacy, their general sense of how to protect that privacy online is often deeply flawed.19 In other words, while many online participants may be digitally literate to some degree, they may not be digitally fluent, and that lack of understanding may impact oral historians' thinking about explaining consent forms and garnering releases going forward. This is one ethical issue for which oral history programs have had to make their own decisions, based on their own specific contexts, their best interpretations of the law, and the OHA's Principles and Best Practices, as well as on their relationship with their chroniclers.

A final topic of ethics conversations in the oral history community is the interviewing of trauma survivors; this is an issue on which well-respected practitioners have very different views, at least as to the timing of such projects. In the last twenty years, a number of oral history collections-focusing on 9/11, the Oklahoma City bombing, Hurricanes Katrina and Rita, and the Joplin tornadoes, among other events - have sprung up in the aftermath of both human-made and natural disasters, and the resulting research has raised questions about a number of issues. When should survivors be interviewed? Should it be immediately on the heels of an event, when their memories may still be fresh, or should they be given time to process and contextualize their experiences? What are the mental health implications of having oral historians being the ones to "debrief" people who have experienced trauma? What training should practitioners have, and what should they be alert for, if they are engaged in this type of 
interviewing? There have been a number of gatherings at the OHA annual meetings that have addressed some of these topics, including a special session in the aftermath of Katrina at the October 2005 conference in Providence, Rhode Island. A search for related posts on the H-Oralhist e-mail list resulted in over 130 mentions of "trauma"; thus, it is an issue that has received considerable discussion over the last few years within the community.20 As with the question of narrator protection, however, there is still disagreement over how to approach this type of interviewing, and the dialogue will continue. These two areas may be the most likely foci of future oral history ethics conversations.

It is clear from the above examples that repositories and practitioners are still struggling with most of these ethical issues, trying to determine how best to address concerns such as institutional control of oral histories, appropriate access, the "letter and spirit" of older release forms, and responsibilities to communities and to individuals. Oral history programs and projects can gain some guidance from the more legislated approaches of IRBs and legal documents, while also seeking advice from the OHA's Principles and Best Practices and the OHA's earlier Evaluation Guidelines. The latter two sources are not intended to provide answers for every possible contingency and are open to a certain amount of interpretation, but they allow flexibility for repositories to follow their own lights as technology evolves. As in any methodology, of course, ethical issues will continue to surface in oral history, but what is important is that individuals and institutions are aware of these issues and have a sense of the relevant parameters and guidelines, so that they have clear points of reference when navigating uncharted waters.

1"2000 Oral History Evaluation Guidelines," Oral History Association, www.oralhistory.org/about/principles-and-practices/oral-historyevaluation-guidelines-revised-in-2000/ (accessed December 15, 2012); “Principles and Best Practices," Oral History Association, http://www.oralhistory.org/about/principles-andpractices/(accessed December 15, 2012).

2Zachary Schrag, Ethical Imperialism: Institutional Review Boards and the Social Sciences, 1965-2009 (Baltimore: Johns Hopkins University Press, 2010); Linda Shopes, "Human Subjects and IRB Review: Oral History, Human Subjects, and Institutional Review Boards," http://www.oralhistory.org/about/do-oral-history/oral-history-and-irb-review/ (accessed December 15, 2012).

3 Title 45 Code of Federal Regulations, Public Welfare, Department of Health and Human Services, Part 46, Protection of Human Subjects, http://www.hhs.gov/ohrp/humansubjects/guidance/45cfr46.html (accessed December 15, 2012).

${ }_{4}$ Confidentiality and risk are currently on the minds of many oral historians as the suit to subpoena restricted Boston College interviews from the Belfast Project makes its way through the courts. It should be noted that, because of the wording of the federal guidelines, oral history projects carrying an obvious and significant level of personal or professional risk may still be interpreted as falling under IRB purview, even if other oral history undertakings are not. If projects with serious risk factors are not covered by IRB oversight, researchers and repositories have a duty to be especially diligent in exercising their responsibilities toward their chroniclers.

5 Donald A. Ritchie and Linda Shopes, “Oral History Excluded from IRB Review," Oral History Association Newsletter 37, no. 3 (2003): 1.

6 Don Ritchie, email to the author, March 30, 2004.

7 "Human Subjects Research FAQs," Smithsonian Institution,

http://www.si.edu/osp/Compliance/Human\%20Subjects\%20in\%20Research/Human\%20Subjects\%20in\%20Research/HUMAN\%20SUBJECTS\%20 RESEARCH\%20FAQs.doc (accessed December 15, 2012).

8 Shopes, "Human Subjects and IRB Review."

${ }_{9}$ For two brief summaries of some of the more important changes, see "Oral History, IRB and Information Risk: A Response to the Federal Proposal," http://www.oralhistory.org/wp-content/uploads/2011/12/IRBproposed-response.pdf or Robert B. Townsend, "Getting Free of the IRB: A Call to Action for Oral History," http://blog.historians.org/news/1382/getting-free-of-the-irb-a-call-to-action (both accessed December 15, 2012).

10 "Human Subjects Research Protections: Enhancing Protections for Research Subjects and Reducing Burden, Delay, and Ambiguity for Investigators," http://www.regulations.gov/\#!docketBrowser;rpp=25; po=0; dct=PS;D=HHS-OPHS-2011-0005 (accessed December 15, 2012). 11 Creative Commons, http://creativecommons.org/ (accessed December 15, 2012).

12 Creative Commons, http://creativecommons.org/choose/ (accessed December 15, 2012).

13 Jack Dougherty and Candace Simpson, "Oral History Interviews-Who Owns Oral History? A Creative Commons Solution,"

http://ohda.matrix.msu.edu/2012/06/a-creative-commons-solution/ (accessed December 15, 2012).

14 "Principles and Best Practices," Post-Interview section, item 7.

15 A general sense of the situation as it stood in the late 1990s can be found in Mary Larson, "Guarding Against Cyberpirates," Oral History Association Newsletter 33, no. 3 (1999): 4-5.

16 An example of this approach is the University of Nevada Oral History Program's "Nevada Voices" site,

http://oralhistory.unr.edu/research_nvvoices.asp (accessed December 15, 2012).

17 California State University at Long Beach's Virtual Oral/Aural History Archive provides an example of rights statements tied to interview pages. The details for use can be clearly seen at the bottom of the web page for Betty Jean Boggs at 
http://symposia.library.csulb.edu/iii/cpro/DigitalltemViewPage.external?lang=eng\&sp=1001526\&sp=T\&sp=1\&suite=def (accessed December 15, 2012).

18 A sample of relevant sessions includes "Ethics, Community, Multimedia, and the Internet" (Oral History Association Annual Meeting, Buffalo, NY, 1998), "Oral History on the Web: Promises and Perils" (Oral History Association Annual Meeting, Little Rock, AR, 2006), and "Oral History on the Web: Promises and Perils (Part 2)" (Oral History Association Annual Meeting, Pittsburgh, PA, 2008).

${ }_{19}$ Chris Jay Hoofnagle et al., "How Different are Young Adults from Older Adults When it Comes to Information Privacy Attitudes and Policies?" Social Science Research Network, http://papers.ssrn.com/sol3/papers.cfm?abstract_id=1589864 (last revised April 17, 2010); Lauren

Magnuson, "Promoting Privacy: Online and Reputation Management as an Information Literacy Skill," College \& Research Libraries News 72 , no. 3 (2011): 137-40.

20 In 2008, the Oral History Review published a particularly thoughtful piece by Stephen Sloan on some of these considerations. "Oral History and Hurricane Katrina: Reflections on Shouts and Silences," Oral History Review 35, no. 2 (2008): 176-86. The statistics cited on the appearance of the term "trauma" come from a search of the H-Oralhist archives, at http://www.h-net.org/ oralhist/, using that word. 